\title{
"A Comparative Study To Evaluate The Effect Of Warm Mustard Oil Vs. Warm Mustard Oil With Camphor On Relief Of Knee Joint Pain Among Rural Women In Selected Areas Of Puducherry."
}

\author{
Ms. Remya Mohan ${ }^{1}$,Prof. Renuka. $\mathrm{K}^{2}$ \\ ${ }^{I}$ MSc Nursing II year, Dept. of Medical Surgical Nursing, Kasturba Gandhi Nursing College, Puducherry \\ ${ }^{2}$ Principal\&HOD, Dept. of Medical Surgical Nursing, Kasturba Gandhi Nursing College, Puducherry
}

\begin{abstract}
:
Background:Osteoarthritis is a common arthropathy of the knee. In India, the prevalence of the disease in the adult rural population is estimated to be $5.8 \%$.

Aim:The main aim of the present study was to compare the effectiveness of warm mustard oil and warm mustard oil with camphor on reduction of knee joint pain among rural women in selected rural areas of Puducherry.

Materials and Methods: A quasi-experimental study (two group pretest and posttest design) done among 60 rural women with knee joint pain. Data were collected using structured questionnaire and modified WOMAC scale. Data analysis was done using inferential and descriptive statistics.

Results:Totally 60 rural women participated in the study. It was observed that majority of the samples were in the age group between 51-55years. Majority of the samples in both group I and group II had moderate level of pain. After warm mustard oil massage and warm mustard oil with camphor massage, the pain level had reduced to mild level in group I and group II respectively. The mean pretest values of pain score in both groups had significant difference during posttest measurement of mean pain score. The coefficient of variance analysis revealed that warm mustard oil with camphor massage reduced the pain level more significantly than warm mustard oil massage.

Conclusion:Knee joint pain is an early symptom of osteoarthritis and it is the leading cause of disability in humans especially in women. Hence efforts like use of warm mustard oil or warm mustard oil with camphor massage which is easily accessible and cost effective methods to reduce the knee joint pain should be made by the community health nurse to bring down the prevalence of knee joint pain.
\end{abstract}

Keywords: Knee joint pain, mustard oil, camphor, WOMAC scale, rural women.

\section{Introduction}

The health of Indian women is intrinsically linked to their status in society. Research on women's status has found that the contributions of Indian women make towards family are overlooked, and instead they are viewed as economic burden.They typically have little autonomy, living under the control of first their fathers, then their husbands, and finally their sons. All of these factors exert a negative impact on the health status of Indian women. (International Research Journal of Social Sciences 2013)Hip and kneeosteoarthritis is one of the leading causes of global disability in women. Globally, of the 291 conditions, hip and kneeosteoarthritis was ranked as the 11th highest contributor to global disability and 38th highest in disabilityadjusted life years (DALYs).Prevalence was higher in females than males. Years of life lived with disability (YLDs) for hip and knee OA increased from 10.5 million in 1990 (0.42\% of total DALYs) to 17.1 million in 2010 (0.69\% of total DALYs) (Global Burden of Disease 2010 Study).

\section{Objectives:}

- To assess the level of knee joint pain among rural women in two groups during pretest.

- To evaluate the effect of warm mustard oil massage and warm mustard oil with camphor massageon relief of knee joint pain among rural women during post test.

- To compare the effectiveness of warm mustard oil massage Vs. warm mustard oil with camphor massage on relief of knee joint pain among rural women.

- To compare the coefficient of variance of warm mustard oil massage and warm mustard oil with camphor massage on reduction of knee joint pain among rural women. 


\section{Research Design}

\section{Materials And Methods}

The research design used in the study was Quasi Experimental Design (Two group pretestposttest design)

\section{Setting of the study}

The study was conducted in Pillaiyarkuppam and Kirumampakkam rural areas of Puducherry. It is 11 $\mathrm{km}$ from Pondicherry town and $1.5 \mathrm{~km}$ away fromKasturba Gandhi Nursing College. The total population of Pillaiyarkuppam is 2282 . Kirumampakkam is a village area which is $1 \mathrm{~km}$ away from Kasturba Gandhi Nursing College. The population covered under Kirumampakkam primary health centre is 23941.

\section{Population and sample size}

The target population of the study was women with knee joint pain. Each group (i.e.) Group I and Group II comprised of 30 rural women with knee joint pain. Totally 60 rural women were selected as samples.

\section{Data collection procedure and analysis}

Samples were selected by purposive sampling technique and divided as group I who received warm mustard oil massage and group II who received warm mustard oil with camphor massage. Rural women were interviewed regarding socio economic and demographic variables by structured questionnaire. Assessment of pain level was done by modified WOMAC scale. Data analysis was done by descriptive and inferential statistics.

\section{Results}

Totally 60 rural women who had knee joint pain during study period were included in the study. Majority of samples 12 (40\%) in group I, $10(33.3 \%)$ in group II belong to the age group of 51-55 years. In terms of Body mass index majority of samples $13(43.3 \%)$ in group I and 28(50\%) in group II had BMI of 2529.9. In terms of occupation majority of women in group I $23(76.7 \%)$ and $12(40 \%)$ in group II were home makers and $7(23.3 \%)$ in group I and $11(36.7 \%)$ in group II were engaged with self-help group functionaries. $7(23.3 \%)$ in group II were farmers or coolie workers. In terms of activity majority of women in group I 14 (46.7\%) had moderate level of activity, 9 (30\%) with mild activity level and $7(23.3 \%)$ were with severe activity level. Whereas in group II majority of women 19 (63.3\%) were with moderate level of activity and $6(20 \%)$ were with severe activity level and 5 (16.7\%) were with mild activity.

Figure I show the distribution of level of pain in rural women with knee joint pain during pre-test and posttest in group I \& II.In pretest out of 30 subjects in group I, 10 (33.3\%) were had mild pain and 20 (66.7\%) were had moderate pain. In group II $2(6.7 \%)$ had mild level of pain and $28(93.3 \%)$ had moderate pain.During posttest after application of warm mustard oil massage, the pain level reduced as mild $53.3 \%$ and moderate 46.7\%. In group II after the application of warm mustard oil with camphor, the pain level reduced to mild $33.3 \%$ and moderate $66.7 \%$.

Figure I: Level of pain in group I and group II

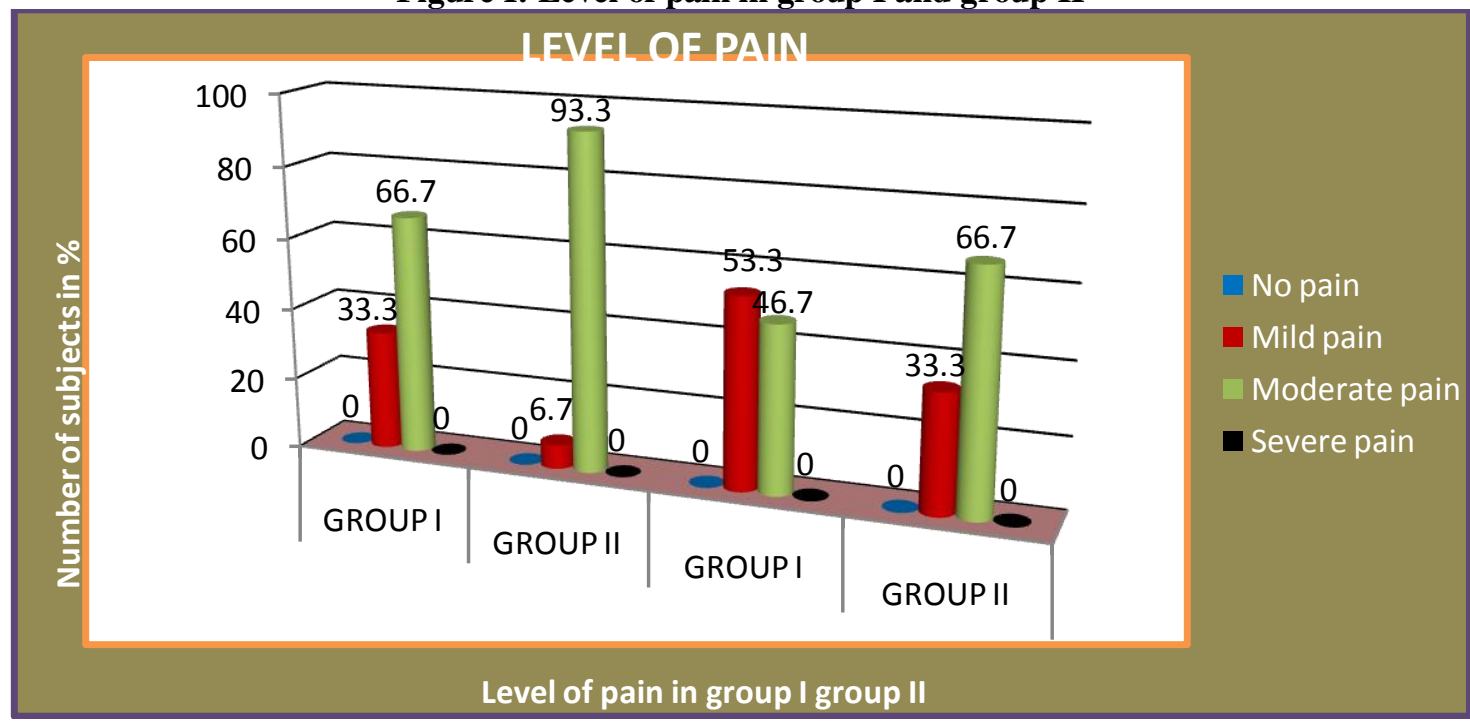


Table I shows the mean pain score among rural women in group I\& II during pretest and posttest. In group I the pre and posttest mean pain score was 33.87 and 29.03and in group II 37.77 and 31.17respectively. The obtained paired ' $\mathbf{t}$ ' value for group I and II was 7.87 and 10.729 and $\mathbf{p}$ value was $0.000 * *$ for both the groups. It was highly significant at $\mathbf{p}<\mathbf{0 . 0 0 1}$ level. It infers that there is significant difference between pre-test and post-test values of pain level in group I and II.

Table I: Description of mean level of pain score among rural women in group I \& II during pretest and post test

\begin{tabular}{|c|c|c|c|c|c|c|c|}
\hline \multirow{3}{*}{ Group I } & Test & Mean & $\begin{array}{c}\text { Mean } \\
\text { difference }\end{array}$ & Std. Deviation & Paired 't' value & df & P value \\
\hline & $\begin{array}{l}\text { pretest pain } \\
\text { score }\end{array}$ & 33.87 & \multirow{2}{*}{4.84} & 9.085 & \multirow{2}{*}{7.87} & \multirow{2}{*}{29} & \multirow{2}{*}{$\begin{array}{c}0.000^{* * * *} \\
\text { (HS) }\end{array}$} \\
\hline & $\begin{array}{l}\text { Posttest } \\
\text { pain score }\end{array}$ & 29.03 & & 7.379 & & & \\
\hline \multirow[t]{2}{*}{ Group II } & $\begin{array}{l}\text { pretest pain } \\
\text { score }\end{array}$ & 37.77 & \multirow{2}{*}{6.6} & 6.151 & \multirow{2}{*}{10.729} & \multirow{2}{*}{29} & \multirow{2}{*}{$\begin{array}{c}0.000^{* * * *} \\
(\text { HS) }\end{array}$} \\
\hline & $\begin{array}{l}\text { Posttest } \\
\text { pain score }\end{array}$ & 31.17 & & 5.459 & & & \\
\hline
\end{tabular}

$* * *$ Highly significant at $\mathbf{p}<0.001$ level

The comparison of effectiveness of warm mustard oil Vs warm mustard oil with camphor was assessed by coefficient of variance. Figure II shows the coefficient of variance of group I was 51.05 and group II was 69.60. It indicates there was increased variation in the level of pain reduction in group II than group I. It revealed that warm mustard oil with camphor reduced the moderate pain level to mild level.

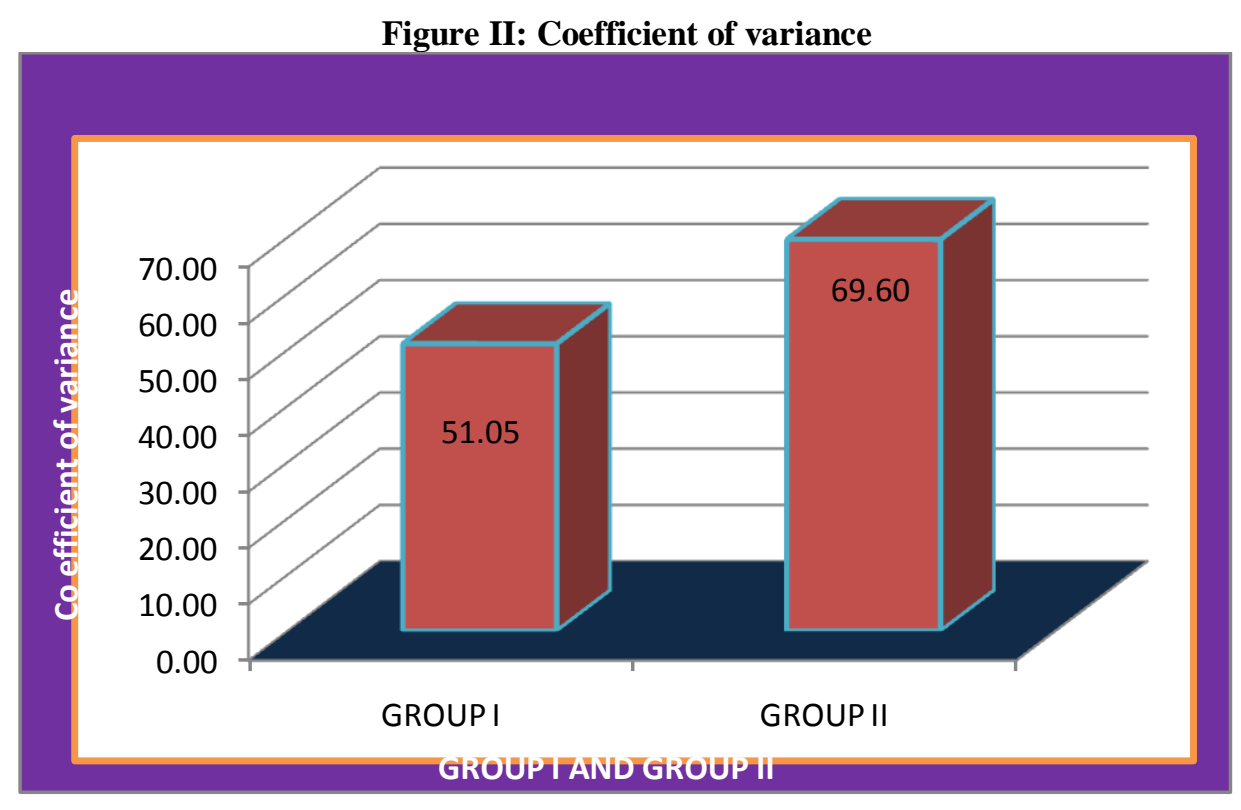

\section{Discussion}

Osteoarthritis is a disease that progresses over time and culminates in the destruction of articular cartilage and joints. It has been shown that women are more severely impacted by osteoarthritis and present for treatment in more advanced stages of osteoarthritis and have more debilitating pain than men (Hame SL2013). The present study done in rural areas of Puducherry and it revealed that rural women above 40 years are more affected with knee joint pain. According to Fenson DT (1991) osteoarthritis is the second most frequent health problem seen in women over the age of 45. A study conducted by Riya Rachel George and Tamilmani at Namakkal district reported that there was significant reduction in knee joint pain after mustard oil massage. In the present study, it was found that warmmustard oil and warm mustard oil with camphor were effective in the management of knee joint pain among rural women. According to Marc Cohen a topical cream containing Glucosamine Sulphate and camphor was effective for osteoarthritis of knee and showed continuous reduction of pain with clinically significant results within four weeks.

Regarding the comparison of effectiveness of warm mustard oil and warm mustard oil with camphor it was found that there was increased variation in the reduction of pain in the samples who had warm mustard oil with camphor massage than warm mustard oil massage alone. 


\section{Conclusion}

Prevalence of knee joint pain is more common in rural areas. The main aim of the present study was to compare the effectiveness of warm mustard oil and warm mustard oil with camphor on reduction of knee joint pain among rural women in selected areas of Puducherry. The samples were divided in to two groups, group I received warm mustard massage and group II received warm mustard oil with camphor massage. The mean pretest pain score of group I was 33.87 and mean posttest pain score was 29.03. The mean pretest pain score of group II was 37.77 and mean posttest pain score was 31.17. And the coefficient of variance 69.60 in group I and 51.05 in group II revealed that there is significant reduction in the pain levels. It infers that warm mustard oil with camphor massage is more effective in reducing knee joint pain in rural women than warm mustard oil massage.

\section{Reference}

[1]. AkhihiroSudo et.al; Prevalence and risk factors for knee osteoarthritis in elderly Japanese men and women; Journal of orthopedic science.13:413, 2008.

[2]. Sunilkumar M et.al; Women Health in India: An analysis; International Journal of Social Sciences; vol 2(10) 11-15, 2013

[3]. DrRajendra Sharma; Musculoskeletal Conditions in India; Indian Council of Medical Research; New Delhi.2012

[4]. Marlene Fransen et.al; The epidemiology of osteoarthritis in Asia; International Journal of Rheumatic Diseases; 14:113-121; 2011 